This document is the accepted manuscript version of the following article:

Allegrini, J., Dorer, V., \& Carmeliet, J. (2015). Coupled CFD, radiation and building energy model for studying heat fluxes in an urban environment with generic building configurations. Sustainable Cities and Society, 19, 385-394. http://doi.org/10.1016/j.scs.2015.07.009

This manuscript version is made available under the CC-BY-NC-ND 4.0 1icense http://creativecommons.org/1icenses/by-nc-nd/4.0/

\title{
Coupled CFD, radiation and building energy model for studying heat fluxes in an urban environment with generic building configurations
}

\author{
Jonas Allegrini ${ }^{\text {a, }}$, Viktor Dorer ${ }^{\text {a }}$, Jan Carmeliet ${ }^{\text {a,b }}$ \\ ${ }^{\text {a }}$ Laboratory for Building Science and Technology \\ Swiss Federal Laboratories for Materials Science and Technology (Empa) \\ Überlandstrasse 129, 8600 Dübendorf, Switzerland \\ ${ }^{\mathrm{b}}$ Chair of Building Physics, Swiss Federal Institute of Technology Zurich (ETHZ), \\ Stefano-Franscini-Platz 5, 8093 Zürich, Switzerland
}

\begin{abstract}
:
In the past decades cities have been continuously growing. The microclimate in urban areas differs significantly from the microclimate in rural areas. The temperatures in urban areas are most of the time higher due to the urban heat island (UHI) effect and the wind speeds are lower due to wind sheltering. The local microclimate strongly influences the space cooling and heating demand of buildings and the human comfort and health in urban areas. The mechanisms causing the UHI effect have to be understood in detail to be able to improve the sustainability of (future) cities and the human comfort in urban areas. Wind driven ventilation is one of the most efficient ways of removing heat from urban areas. Knowledge of the heat fluxes caused by wind driven ventilation is important to be able to optimize the design of urban areas in terms of heat removal. The heat removal by wind and buoyancy can be increased by choosing optimal building geometries. In this study the urban heat fluxes are studied for six generic urban morphologies. Coupled CFD (computational fluid dynamics) and building energy simulations are conducted. This approach has the advantage of having highly spatially resolved temperature and flow fields and therefore being able of determining heat fluxes. Turbulent and convective heat fluxes are considered. The results show the importance of buoyancy for low wind speed cases and the strong influence of buildings upstream on the heat fluxes and temperatures further downstream.
\end{abstract}

\section{Keywords}

Urban heat island effect, CFD, Building energy simulation, Comfort, Microclimate, Urban Design, Heat Fluxes

Corresponding author: Jonas Allegrini, Empa Dübendorf, Ueberlandstrasse 129, 8600 Dübendorf, Switzerland. Tel.: +41 (0) 587656512 , Fax: +41 (0) 5876540 09, e-mail: jonas.allegrini@empa.ch

\section{Introduction}

The microclimate in urban areas differs significantly from the climate in rural areas. The air temperatures are higher due to the urban heat island (UHI) effect and the wind speeds are lower due to wind sheltering (Oke 1987). The UHI effect is mainly caused by reduced sky view factors, materials with high heat capacity, anthropogenic heat, lack of evapotranspiration and reduced turbulent 
convection (Santamouris 2001a). Measurements in London showed up to $7 \mathrm{~K}$ higher air temperatures at night-time in the city compared to measurements outside the city (Watkins et al. 2002). In Athens the mean heat island intensity exceeds $10 \mathrm{~K}$, which can double the energy demand for space cooling in buildings (Santamouris et al. 2001b). Global warming and associated heat waves (Schär et al. 2004; Fischer and Schär, 2009) may further increase the temperatures in urban areas and can reduce the potential for night cooling significantly. The UHI effect not only influences the energy demand for space cooling and heating of buildings, but has also a large impact on the thermal comfort and health of the people living in urban areas.

Knowledge of the detailed urban microclimate is important for a wide number of applications. For example to get accurate results for building energy simulations, accurate microclimatic data at the building site are needed. Also city planners need finely resolved climatic data to improve the thermal comfort in existing urban areas or for planning new urban areas with high thermal comfort. A wide range of studies on the microclimate can be found in literature. Arnfield 2003, Mirzaei and Haghighat 2010 and Moonen et al. 2012a give overviews over a large number of microclimate studies in the literature. There are mainly two types of studies: field measurements in urban areas and numerical simulations based on radiation, flow and building simulations. Recent microclimate studies based on CFD simulations have been conducted e.g. by Toparlar et al. 2015 and Gromke et al. 2015. The numerical simulations mostly focus on evaluating air and surface temperatures and comfort criteria for specific urban areas (e.g. Ali-Toudert and Mayer 2006, Taleghani et al. 2014, Saneinejad et al. 2014). Although heat fluxes could be extracted from most of these simulations, they are not analysed and presented. A number of field measurements have been performed, where heat fluxes were measured (e.g. Offerle et al. 2006, Rotach et al. 2005, Allwine and Flaherty 2006). Offerle et al. 2006 studied heat fluxes near the city centre of Lodz (Poland). They measured and analysed the different heat fluxes (radiative heat fluxes, anthropogenic heat fluxes, turbulent latent heat fluxes, turbulent sensible heat fluxes etc.) and compared them for different days within two years. Field measurements give very detailed information on a specific site. The disadvantage is that it is difficult to draw general conclusions. Field measurement campaigns are also very complex and costly. With numerical simulations on the other hand, a large number of different urban morphologies can be simulated to come to more general conclusions. Also different morphologies can be evaluated before they are built at a specific site. Another advantage of numerical simulations is the high resolution of the results compared to the point measurements of field measurements. With the highly spatially resolved results, also fluxes through planes can be determined and therefore heat fluxes can be tracked from their source to the vicinity of the urban area. According to our best knowledge, there exists no detailed numerical study that focuses on heat fluxes within urban areas. There exist a large number of studies on air exchange rates and dispersion studies in the context of pollution that also give valuable information on possible heat fluxes. Moonen et al. 2012a present an overview on pollution dispersion studies in their review paper on urban physics. Buccolieri et al. 2010 studied the ventilation efficiency of urban-like geometries by estimating the mean age of air that is commonly used for indoor studies. They found stronger recirculation zones and larger mean age of air for more compact cities. Hu and Yoshie 2013 evaluated the ventilation efficiency using 
the visitation frequency and inflow and outflow rates of pollutants. Based on their results they proposed a "Passage Ratio" to evaluating the ventilation efficiency. Another study, where exchange rates of air were studied was conducted by Moonen et al. 2011. They used a courtyard geometry and analysed the air exchange rate at its top and mid planes. Their results show a strong dependency of the exchange rates on the courtyard length and the incident angle of the wind. Hall et al. 2012 developed a simplified model to calculate the same exchange velocity for street canyons to be used by urban planners. Finally Moonen et al 2012b performed a CFD study, where they determined the flow through different planes in an urban area with courtyards depending on different wind directions.

The aim of this study is to analyse the heat fluxes within and at the boundaries of urban areas. To improve the wind driven ventilation for future cities and city quarters, city planners have to know, how to influence the heat fluxes within urban areas. With this knowledge they can optimize building geometries and locations for vegetation (e.g. trees) to maximize the removal of heat in urban areas. In this study heat fluxes for six urban morphologies are analysed as a first step. Similar studies for a wide range of cases have to be conducted in future to derive more general conclusions that can be used by urban designers. The focus of this study is not on a detailed quantification of heat fluxes for a specific case, but the comparison of the heat fluxes for different cases. Most of the heat fluxes in urban areas are induced by absorption of solar radiation on building and ground surfaces. In this study building energy simulations (BES) with detailed solar and longwave radiation models are conducted to determine the surface temperatures in the studied urban areas. CFD simulations are conducted with the surface temperatures from BES to determine the heat fluxes in the air domain. Using CFD has the advantage of having highly spatially resolved temperature and flow fields that are needed to determine heat fluxes. Heat fluxes through different planes within and at the boundaries of urban areas are studied. Results from these simulations are also reported in Allegrini et al. 2015, where we analysed mainly the resulting surface and air temperatures. In this paper however, we focus on the analysis of the heat fluxes trying to further understand the mechanisms of heat removal.

To study the total heat flux through a plane, the turbulent heat flux (here including the heat conduction) and the convective heat flux are considered:

$$
\begin{gathered}
Q_{\text {conv }}=\int u\left(T-T_{\infty}\right) c_{p} \rho d A \\
Q_{\text {turb }}=\int k_{\text {eff }} \frac{\Delta T}{\Delta n} c_{p} \rho d A
\end{gathered}
$$

Here $Q_{c o n v}$ is the convective heat flux, $u$ the velocity normal to the plane, $T$ the temperature, $T_{\infty}$ a reference temperature (here approach flow temperature), $c_{p}$ the heat capacity, $\rho$ the density, $k_{\text {eff }}$ the effective thermal conductivity consisting of the thermal conductivity and the turbulent thermal conductivity and $n$ the direction normal to the plane.

The heat fluxes are studied and compared for two approach flow wind speeds. As a first step, here only one wind direction is studied. The wind direction is chosen to be the most critical direction for ventilation purposes. Also the influence of the heat fluxes on the air temperatures within the urban areas is studied. 


\section{Numerical model}

The simulations presented in this paper are conducted for six different generic urban morphologies (Figure 1) for the climate of Zürich (Switzerland). The number of buildings of each morphology is limited by the available computational resources needed for the CFD simulations. All buildings have a height $(\mathrm{H})$ and a width $(\mathrm{W})$ of $10 \mathrm{~m}$ and are between $10 \mathrm{~m}$ and $70 \mathrm{~m}$ long (L). The distance between the buildings (D) is $10 \mathrm{~m}$, leading to a canyon aspect ratio (H/D) of 1 . The ground surface between the buildings is modelled as asphalt. In BES all buildings are modelled as office buildings with corresponding occupancies and internal gains (SIA 2006). Ventilation and infiltration are considered. The glazing (G-value: 0.7 , U-value: $1.1 \mathrm{~W} / \mathrm{m}^{2} \mathrm{~K}$ ) fraction of the buildings is $50 \%$ and all façades have a solar reflectance of 0.5 . The walls have a $U$-value of $0.25 \mathrm{~W} / \mathrm{m}^{2} \mathrm{~K}$ (with outer insulation), the roofs have a U-value of $0.29 \mathrm{~W} / \mathrm{m}^{2} \mathrm{~K}$ and the floors a U-value of $0.3 \mathrm{~W} / \mathrm{m}^{2} \mathrm{~K}$. External shading devices are used to protect the buildings from solar gains. They close when the solar irradiation on the corresponding façade is $>150 \mathrm{~W} / \mathrm{m}^{2}$ and reopen when it is $<50 \mathrm{~W} / \mathrm{m}^{2}$. Each building consists of five thermal zones. Each thermal zone consists of one exterior building wall (or roof) and the associated part of the building volume. The five zones are assumed to have the same inside air temperature. Space heating and space cooling (with no capacity limits) keep the inside air temperature between $21^{\circ} \mathrm{C}$ and $26^{\circ} \mathrm{C}$.

CFD simulations are conducted for a weather condition with a rather high ambient temperature of $25.5^{\circ} \mathrm{C}$, when it is important that heat is removed from the urban areas. The CFD simulations of this study have not directly been validated. Toparlar et al. 2015 presented a validation study, which showed that CFD simulations can accurately predict the urban microclimate, if they are setup carefully. We also conducted a validation study for buoyant flows in street canyons (Allegrini et al. 2014). In this study CFD simulations were validated with wind tunnel measurements. For the present study similar numerical models were used as for the validation study of buoyant flows in street canyons, and as such we are confident of the satisfactoriness of our CFD results. At ground and building surfaces, the temperatures as determined by the BES are imposed. The ground temperature outside the urban areas is set to the ambient air temperature to avoid heating up of the air in the approach flow. For the near-wall modelling, standard wall functions (Launder and Spalding 1974) with no-slip boundary condition were used as a compromise between accuracy and computational cost. The possible overestimation of the wall heat flux at the building façades due to using wall functions (Allegrini et al. 2012) is assumed to be similar for all studied cases. As mentioned above the aim of this study is not a detailed quantification of heat fluxes for a specific case, but the comparison of the heat fluxes for different cases for which the same models with the same limitations are used.

At the inlet (north of the urban areas) of the computational domain vertical profiles of the mean horizontal wind speed, the turbulent kinetic energy and the turbulence dissipation are imposed for two wind speeds, $1 \mathrm{~m} / \mathrm{s}$ and $5.5 \mathrm{~m} / \mathrm{s}$ at $10 \mathrm{~m}$ height. The wind direction is for all cases from the North. These profiles represent an atmospheric boundary layer, where the turbulence originates only from friction and shear (Richards and Hoxey, 1993): 


$$
\begin{aligned}
U(y) & =\frac{u_{A B L}^{*}}{k} \ln \left(\frac{y+z_{0}}{z_{0}}\right) \\
k(y) & =\frac{u_{A B L}^{*}}{\sqrt{c_{\mu}}} \\
\varepsilon(y) & =\frac{u_{A B L}^{*}}{k\left(y+z_{0}\right)}
\end{aligned}
$$

Here $\mathrm{u}_{\mathrm{ABL}} *$ is the atmospheric boundary layer friction velocity, $\mathrm{y}$ the height above the ground, $\mathrm{z}_{0}$ the aerodynamic roughness length, $\mathrm{k}$ the turbulent kinetic energy, $\varepsilon$ the turbulence dissipation rate, $\mathrm{U}$ the mean streamwise velocity and $\mathrm{C}_{\mu}$ a constant of the turbulence model.

Blocken et al. 2007 showed that the shape of the boundary layer profiles changes in the flow direction when wall functions are used at the ground surfaces. They showed that this change can be limited when the ground surfaces are modelled as rough surfaces. The limitation of this approach is that the roughness height has to be smaller than the distance from the centre point of the walladjacent cell to the wall. This requirement conflicts with the fine meshes used in this study. Here the ground surfaces are modelled as smooth walls. Therefore there are small streamwise gradients in the vertical mean wind speed and turbulence profiles. These gradients can however be tolerated, since to study is not on real but generic cases. The approach flow profiles have to correspond to atmospheric boundary layer profiles, but they don't have to match with a specific measured profile at a certain position. In this study the streamwise gradients are also quite small and are the same for all studied cases.

At the sides and top of the computational domain a symmetry boundary condition is applied. At the outlet an outflow boundary condition is used, which assumes that there are no streamwise gradients at the outlet.

The computational domain extends $5 \mathrm{H}$ upstream and $10 \mathrm{H}$ downstream of the building group. In vertical direction the domain is $10 \mathrm{H}$ high. These dimensions are in agreement with best practice guidelines (Franke et al. 2011; Tominaga et al. 2008).

Structured grids are built based on a grid sensitivity analysis. The grids are refined towards the walls to resolve the boundary layers. They consist of 3.7 - 9.9 million cells. For the lower wind speed used in this study, the $\mathrm{y}+$ values were $<500$; for the higher wind speed, $\mathrm{y}+$ values up to 1500 can be found locally. By conducting simulations with a finer mesh it was verified that these rather high $\mathrm{y}+$ values did not cause grid dependent results. A part of the computational grid is given in Figure 2.

\section{Numerical simulation}

\subsection{Radiation and building energy simulation}

For the BES CitySim (Kämpf 2009) is used. CitySim is a simulation tool which models the energy fluxes in a city, with a size ranging from a small neighbourhood to an entire city. In CitySim detailed radiation models for solar and longwave radiation are implemented that can account for the radiation exchange between neighbouring buildings, the ground and environment. The Perez All Weather (Perez et al. 1993) and the Simple Radiosity algorithm (Robinson and Stone, 2006) are used to compute hourly irradiations of short and longwave radiation on building surfaces. Multiple 
iterations for the radiation calculations are performed to achieve consistent results. The heat flow through the walls is determined with a model based on the analogy with an electrical circuit (resistor-capacitor network). The windows are considered as a building surface, but not represented geometrically, therefore no window surface temperature is determined and the temperature of the wall is used for the whole façade. For the convective heat transfer coefficients (CHTC) CitySim uses the correlations by McAdams (1954). Because the CHTC are not an input in the current CitySim version, the heat fluxes from the CFD simulations of this study cannot be used in CitySim. In future CitySim versions it will be possible to set the CHTC as an input. This would then allow for a direct coupling of BES and CFD. CitySim uses an hourly timestep, which cannot be changed. To get individual temperatures for the individual facades and the roof of a building, each building is modelled as a multizone building with a zone for each facade and roof. CitySim also includes HVAC and energy conversion system models (Robinson, 2011). In contrast to the standard CitySim version, in the version used here, a heat balance is solved for the ground surfaces between the buildings. This heat balance includes short and longwave radiation and storage of heat as well as heat conduction to the soil. To model the heat storage and heat conduction of the ground, a number of ground layers are defined with the thickness, the heat conductivity and the heat capacity as input parameters.

\subsection{CFD}

To study the urban microclimate, 3D steady RANS (Reynolds-Averaged Navier-Stokes) CFD simulations are conducted with a k- $\varepsilon$ turbulence model with OpenFOAM. To account for buoyancy the Boussinesq approximation is used. Second-order discretization schemes as well as the SIMPLE algorithm for pressure-velocity coupling are employed. Pressure interpolation is of second order.

\section{Results}

\subsection{Heat fluxes through the boundaries of the urban areas}

\subsubsection{Control volumes}

In the first part of this study the heat fluxes through the boundaries of the urban areas are analysed. There are several ways to define the boundaries. The most straightforward possibility is to define a volume with boundaries containing the outer surfaces of the urban areas. This approach is found to be sensitive to errors when determining the heat balances within this volume. These errors are caused by interpolation of velocity in areas with high gradient. Another reason is that when the flow is almost parallel to the planes in these areas, this leads to errors when determining the out of plane velocity components. To avoid these problems, two different control volume approaches are defined. One control volume (Figure 3) is slightly larger and one (Figure 4) slightly smaller than the urban areas. For the larger control volume the distance between the boundaries of the control volume and the outer building surfaces is $2 \mathrm{~m}(0.2 \mathrm{H})$. For the smaller control volume, the distance between the boundaries of the control volume and the outer building surfaces at the top and sides (East and West) is $0.3 \mathrm{~m}(0.03 \mathrm{H})$. At the inflow and outflow planes, the boundaries are flush to the outer building surfaces. For the two control volumes different results can be found. Therefore more information can be gained by using two instead of one control volume. 
For the determination of the heat balances, the wall heat fluxes at the (heated) building and ground surfaces are considered. When comparing the heat entering the control volume through the inflow or from the building and ground surfaces and the heat leaving the urban areas through the boundaries, errors of up to $5 \%$ can be found depending on the used control volume. These errors are acceptable for the purpose of this study, because here results for different urban morphologies are compared and these differences are significantly larger than the numerical errors.

\subsubsection{Control volumes: larger than urban areas}

In this section the results for the control volume that is slightly larger than the urban areas are discussed. In Figure 5 relative heat fluxes (sum of turbulent and convictive heat fluxes) to the environment through the four boundaries for six urban morphologies are given for the higher wind speed case. Relative heat fluxes mean that for each boundary the sum of the heat fluxes is divided by the total heat flux from the control volume to the environment, which allows to more generalize our results with respect of similar urban configurations. No results are given for the inflow boundary, because here only the fluxes from the control volume to the environment are considered for the total fluxes. Most of the heat of the warm building surfaces is leaving the urban areas through the top and outflow boundaries. Only a minor part of the heat is leaving the urban areas through the lateral boundaries (East and West). For the aligned cubical buildings (A) most of the heat is flowing downstream. The part of the heat flux that leaves the urban area through the top increases for more elongated and staggered instead of aligned building arrangements. The lowest value for the heat leaving the urban area through the outflow boundary can be found for the street canyons (D). There is still a part of the heat flux leaving the urban area through the outflow boundary, because the outflow boundary is $2 \mathrm{~m}$ further downstream from the most southerly façade. At the top boundary most of the heat exchange is due to turbulence. The urban morphology with the largest convective part of the heat flux at the top boundary is the staggered block arrangement (C). For that arrangement the flow is blocked and part of the air flows over the buildings. For the street canyons (D) the part of heat leaving at the top boundary by convection is rather low, because a standing vortex is formed inside the street canyons. The heat exchange inside the shear layer is then mainly due to turbulence. There is no continuous downstream flow. For the staggered blocks (C) there is no vortex that dominates the flow structure, but a continuous downstream flow, where due to the blockage, part of the air flows over the buildings. For higher wind speeds boundary turbulence is more important for the heat exchange at the top than convection. Due to the relatively high wind speeds, the buoyancy effects are smaller and the flow between the buildings is decoupled from the flow above the buildings. Between the two flow regions a shear layer is formed, where turbulence is produced. Most of the heat exchange at the top boundary is therefore driven by this turbulence production.

Figure 6 shows the same kind of results as Figure 5 for the lower wind speed case. For lower wind speeds, buoyancy becomes more important and therefore the results are different compared to the results for the higher wind speeds presented above. The heat fluxes through the lateral boundaries from the urban area to the outside environment are also here very low. The part of the heat flux through the top boundaries is higher compared to the higher wind speed case. This is due to stronger buoyancy effects. The differences between the different urban morphologies are smaller for the 
lower wind speed case, because the strength of the buoyancy effects is similar for the different geometries due to similar surface temperatures for all cases. Here the convective heat fluxes are more important at the top boundaries compared to turbulent heat fluxes. This is opposite compared to the higher wind speed case. Due to buoyancy there is an upwards flow from the urban area to the environment for the lower wind speed case. The flow between the buildings and above the buildings is less decoupled compared to the higher wind speed case. The morphology with the aligned cubical buildings (A) and the morphology with the small street canyons surrounded by cubical buildings (B) show almost the same results (Figure 7 left). This means that the higher blockage of the second morphology does not influence the relative heat fluxes. The wind speeds are found to be lower due to the blockage and thus the air temperatures are higher for the morphology with the small street canyons.

\subsubsection{Control volumes: smaller than urban areas}

Here the results for the control volumes that are slightly smaller than the urban areas are given. Figure 7 depicts the same kind of results as in Figure 5 but for the smaller control volumes. Compared to the larger control volumes (above), the part of the heat fluxes through the top boundaries are smaller. This is mainly due to the fact that here the heat fluxes from the roofs to the environment are not considered within the control volumes. For the street canyons (D) there are no downstream heat fluxes, because the outflow boundary coincides with the most southerly building façade. The differences between the different urban morphologies are larger for the smaller control volumes. For the larger control volumes, an important part of the heat leaving the control volume through the top was originating from the roofs of the buildings. This heat flux is in a similar range for all morphologies. For the smaller control volumes, the roofs are not inside the control volumes. At the top boundaries the convective heat fluxes are larger compared to the turbulent heat fluxes. This means that heat is transported inside the urban areas upwards by convection and is later exchanged by turbulence inside the shear layer, leading to the higher turbulent part for the larger control volumes. For the smaller control volumes the results for the lower wind speed case are not given, because they do not lead to any further conclusions.

\subsection{Heat fluxes through a vertical plane}

In a next step, the heat fluxes through a vertical plane (Figure 8), that is normal to the main flow direction, are studied. The plane is exactly as high and wide as the urban areas. The heat fluxes are not normalized by the area, to avoid jumps in the results, where the cross sections of the flow change in flow direction due to different blockage of the flow by buildings.

In Figure 9 the total heat fluxes through the vertical plane as well as the heat fluxes divided by the numerically integrated upstream wall heat fluxes are given for different downstream positions. A wide range of values for the heat fluxes for the different urban morphologies can be found. For the aligned cubical buildings (A) most of the heat is flowing downstream (see also above). Therefore the total heat fluxes within the urban area are increasing with increasing downstream positions. The increase is almost linear, because the integrated upstream heat fluxes are also increasing almost linearly. The right figure shows that the part of heat flowing downstream is constant over the length of 
the urban area. For the urban morphology with a short street canyon surrounded by cubical buildings (B), the results are the same as for the morphology discussed above until $\mathrm{y} / \mathrm{H}=1.5$. From $\mathrm{y} / \mathrm{H}$ $=1.5$ on the part of downstream heat flux is significantly lower for the morphology with the short street canyon (B). The difference between the results of these two morphologies is caused by the heat fluxes leaving the urban area through the top. This means that already small increase of blockage can cause that more heat is removed from the urban area through the top. But at the same time the flow is slower and therefore the air can heat up more (see below). For the staggered arrangement of cubical buildings $(\mathrm{C})$, the heat flux is first increasing and becomes further downstream more constant with increasing distance from the inflow. This also leads to a decreasing relative heat flux (right figure). This means that for the staggered arrangement of blocks (C), already after a small number of building rows the heat fluxes are fully developed in the downstream wind direction.

Figure 10 shows the same results as Figure 9 for the lower wind speed case. The heat fluxes for the lower wind speed case are by almost a factor of 4 lower compared to the heat fluxes for the higher wind speed case. Due to the lower local wind speeds close to the building surfaces, the convective heat transfer at the building surfaces is lower. The heat fluxes increase less as a function of the downstream position compared to the higher wind speed case. The reason is that the convective heat transfer at the buildings surfaces are lower. High fluctuations for the courtyards can be found. These fluctuations are caused by standing vortices inside the courtyards. For all morphologies the relative heat fluxes in downstream direction are smaller compared to the higher wind speed case. This is due to the higher heat fluxes through the top boundary due to stronger buoyancy effects. The differences between the morphology with aligned cubical buildings (A) and the morphology with a street canyons surrounded by cubical buildings (B) are smaller compared to the higher wind speed case, because of the higher buoyancy effects that have a similar strength for the two morphologies. For all morphologies the relative heat fluxes are decreasing with increasing downstream distance from the first building row due to the removal of heat through the top boundary caused by the buoyancy effects.

\subsection{Averaged velocities and temperatures on a vertical plane}

Finally the mean velocities and temperatures on the same vertical planes as defined above are analysed. For the velocities only the component normal to the planes is considered.

Figure 11 gives the average downstream velocities (normalised by $\mathrm{U}_{10}$ ) and average air temperatures on a vertical plane at different downstream positions. Strong fluctuations of the average downstream velocities and air temperatures can be observed. These fluctuations are caused by the change of the cross section depending on the building density in the vertical plane. The flow is accelerated between the buildings, causing fluctuations in velocity and temperature. For most morphologies the wind speeds are not further decreasing after two rows of buildings. The temperatures on the other hand are increasing for the whole urban areas. Larger urban areas would need to be studied to investigate, if there exists an equilibrium for the air temperature. A clear correlation between the velocities and the air temperatures can be found. For areas with low velocities, the temperatures are higher. For the morphology with staggered cubical buildings $(\mathrm{C})$, the velocities are lower compared to 
the morphology with the aligned cubical buildings (A). Due to the lower velocities, the temperature increases stronger in downstream direction. Although for the staggered arrangement (C) more heat is leaving the urban area through the top boundary (see above), the temperatures are higher compared to the aligned arrangement (A) due to lower wind speeds. Comparing the morphology with the aligned cubical buildings (A) with the arrangement with the street canyon surrounded by cubical buildings (B), a significant decrease of the wind speeds and an increase of the temperatures can be found due to the blockage of the street canyon.

Figure 12 presents the same results as Figure 11 for the lower wind speed case. The results are similar as for the higher wind speed case discussed above. The velocity fluctuations are higher compared to the higher wind speed case. The increase of the temperatures in downstream direction is slightly lower compared to the higher wind speed case. The reasons for these observations are the buoyancy effects that accelerate the vertical flow. Because more heat is leaving the urban areas through the top boundary and is not flowing further downstream, there is a smaller temperature increase in downstream direction.

\section{Discussion}

In this paper heat fluxes in urban areas were studied by performing one-way coupled BES and CFD simulations. The study shows interesting results, but to draw more general conclusions and to give valuable information to the city planners a large number of additional simulations should be conducted. This study is considered as a first step of a more complete analysis of heat fluxes in urban areas. Here simulations were conducted for only one wind direction. Also oblique flow directions should be considered, because the wind direction has a large impact on the heat fluxes within urban areas. In general the heat fluxes for a larger number of weather conditions with different surface and air temperatures and wind speeds and wind directions have to be evaluated to analyse the urban microclimate for the whole year. Also a wider range of building geometries (e.g. non-uniform building heights or more detailed geometries of the individual buildings) could lead to additional information on the urban microclimate. Here only steady CFD simulations were conducted. With unsteady CFD simulations more (accurate) information on the ventilation of the urban areas could be gained (Moonen et al. 2011). And finally, because only small groups of buildings were studied, the flow and temperature fields were still developing in downstream direction. The size of the urban areas was limited by the available computational resources. For larger urban areas less cold air can enter the urban areas from the side and upstream and therefore higher air temperatures could be reached within the urban areas.

\section{Conclusion}

Heat fluxes for six different urban morphologies were studied with CFD (computational fluid dynamics) and building energy simulations (BES). The information on detailed heat fluxes in urban areas for different geometries can help city planners to optimize the building geometries in increase the heat removal from urban areas. A BES model was used to determine the surface temperatures of the buildings and the ground within the urban areas. In the BES model short and longwave radiation, convective heat transfer at the surfaces and heat conductance through the walls and ground are 
considered. CFD simulations were conducted to predict the temperature and flow fields, where the surface temperature determined with the BES are used as boundary conditions. For the heat fluxes, turbulent and convective fluxes are considered. The results show that most heat is leaving the urban areas through the top or in downstream direction. With increasing blockage of the wind by buildings, the heat fluxes through the top boundary get more important. Although with higher blockage more heat can be removed through the top plane and therefore a smaller part of the heat is transported downstream by convection, the air temperatures are higher for urban areas with higher blockage due to lower wind speeds. Dependent on the wind speed of the approach flow either turbulence or convection is more important for the heat exchange at the top plane of the urban areas. For higher wind speed the heat is transported to the building roof levels by convection and then removed by turbulent mixing with the flow above the roofs. For lower wind speed buoyancy is more important. Due to buoyancy a larger part of the heat is removed through the top for the lower wind speeds compared to the higher wind speeds. Also the heat is removed by convection and not turbulent mixing as for the higher wind speed case.

Already small differences in the blockage upstream can cause rather large changes in the heat fluxes, temperatures and velocities further downstream. With an increase of the blockage upstream, more heat is removed through the top and less heat is transported downstream by convection. This shows the importance of accounting for the buildings in upstream directions for accurate simulations. This effect gets less important for lower wind speeds, when the flow is mainly driven by buoyancy.

Acknowledgments

Funding by EU Climate-KiC (Project Smart Urban Adapt) and CCEM (Project Urban Multi-scale Energy Modelling) is gratefully acknowledged.

\section{References.}

Ali-Toudert, F., Mayer, H., 2006. Numerical study on the effects of aspect ratio and orientation of an urban street canyon on outdoor thermal comfort in hot and dry climate. Build. Environ. 41, 94108.

Allegrini, J., Dorer, V., Carmeliet, J., 2012. An adaptive temperature wall function for mixed convective flows at exterior surfaces of buildings in street canyons. Build. Environ. 49, 55-66.

Allegrini, J., Dorer, V., Carmeliet, J., 2014. Buoyant flows in street canyons: Validation of CFD simulations with wind tunnel measurements. Build. Environ. 72, 63-74.

Allegrini, J., Dorer, V., Carmeliet, J., 2015. Influence of morphologies on the microclimate in urban neighbourhoods. J. Wind En. Ind. Aerod. 49, DOI: 10.1016/j.jweia.2015.03.024

Allwine, K.J., Flaherty, J.E., 2006. Joint Urban 2003: Study Overview and Instrument Locations. Pacific Northwest National Laboratory Richland, Washington 99352

Arnfield, J, 2003. Two decades of urban climate research: a review of turbulence, exchanges of energy and water, and the urban heat island. Int. J. Climatol. 23, 1-26. 
Blocken B, Stathopoulos T, Carmeliet J., 2007. CFD simulation of the atmospheric boundary layer: wall function problems. Atmos. Environ. 41(2): 238-252.

Buccolieri, R., Sandberg, M., Di Sabatino, S., 2010. City breathability and its link to pollutant cencentration distribution within urban-like geometries. Atmospheric Environment 44, 1894-1903.

Fischer, E.M., Schär, C., 2009. Future changes in daily summer temperature variability: driving processes and role for temperature extremes. Clim. Dynm. 33, 917-935.

Franke, J., Hellsten, A., Schlünzen, H., Carissimo, B., 2011. The COST 732 best practice guideline for CFD simulation o flows in the urban environment: a summary. Int. J. Environ. Pollut. 44 (1-4), 419-427.

Gromke, C.B., Blocken, B., Janssen, W.D., Merema, B., van Hooff, T., Timmermans, H.J.P., 2015. CFD analysis of transpirational cooling by vegetation: Case study for specific meteorological conditions during a heat wave in Arnhem, Netherlands. Build. Environ. 83, 11-26.

Hall, T.C., Britter, R.E., Norford, L.K., Predicting velocities and turbulent momentum exchange in isolated street canyons. Atmospheric Environment 59, 75-85.

Hu, T., Yoshie, R., 2013. Indices to evaluate ventilation efficiency in newly-built urban area at pedestrian level. J. Win Eng. Ind. Aerodyn. 112, 39-51.

Kämpf, J., 2009. On the modelling and optimisation of urban energy fluxes, $\mathrm{PhD}$ thesis $\mathrm{n}^{\circ} 4548$ EPF Lausanne, Lausanne.

Launder, B.E., Spalding, D.B., 1974. The numerical computation of turbulent flows. Comput Method Appl M Eng 3, 269-289.

McAdams, W.H., 1954. Heat Transmission, McGraw-Hill Kogakusha, Tokyo.

Mirzaei, PA, Haghighat, F., 2010. Approaches to study urban heat island e abilities and limitations. Build. Environ. 45, 2192-201.

Moonen, P., Dorer, V., Carmeliet, J., 2011. Evaluation of the ventilation potential of courtyards and urban street canyons using RANS and LES. J. Wind En. Ind. Aerod. 99, 414-423.

Moonen, P., Defraeye, T., Dorer, V., Blocken, B., Carmeliet, J., 2012a. Urban Physics: Effect of the micro-climate on comfort, health and energy demand. Frontiers of Architectural Research1, 197228.

Moonen, P., Dorer, V., Carmeliet, J., 2012b. Effect of flow unsteadiness on the mean wind flow pattern in an idealized urban environment. J. Wind Eng. Ind. Aerodyn. 104-106, 389-396.

Offerle, B., Grimmond, C.S.B., Fortuniak, K., Klysik, K., Oke, T.R., 2006. Temporal variations in heat fluxes over a central European city centre. Theor. Appl. Climatol. 84, 103-115.

Oke, T.R., 1987. Boundary Layer Climates, second ed. Methuen, London.

Perez, R., Seals, R., Michalsky, J., 1993. All-weather model for sky luminance distribution preliminary configuration and validation. Sol. Energy 50 (3), 235-243. 
Richards, P.J., Hoxey, R.P., 1993. Appropriate boundary conditions for computational wind engineering models using the k- $\varepsilon$ turbulence model. J. Wind En. Ind. Aerod. 46-47, 145-153.

Robinson, D., Stone, A., 2006. Internal illumination prediction based on a simplified radiosity algorithm. Sol. Energy 80 (3), 260-267.

Robinson, D., 2011. Computer Modelling for Sustainable Urban Design: Physical Principles, Methods and Applications, Earthscan, London.

Rotach, M.W., Vogt, R., Bernhofer, C., Batchvarova, E., Christen, A., Clappier, A., Feddersen, B., Gryning, S.E., Martucci, G., Mayer, H., Mitev, V., Oke, T.R., Parlow, E., Richner, H., Roth, M., Roulet, Y.A., Ruffieux, D., Salmond, J.A., Schatzmann, M., Voogt, J.A., 2005. BUBBLE - an Urban Boundary Layer Meteorology Project. Theor. Appl. Climatol. 81, 231-261.

Saneinejad, S., Moonen, P., Carmeliet, J., 2014. Coupled CFD, radiation and porous media transport model for evaluating micro-climate in an urban environment. J. Wind En. Ind. Aerod. 128, $1-11$.

Santamouris, M., 2001a. Energy and climate in the urban built environment, James \& James, London.

Santamouris, M., Papanikolaou, N., Livada, I., Koronakis, C., Georgakis, A., 2001b. On the impact of urban climate on the energy consumption of buildings. Sol Energy 70 (3), 201-216.

Schär, C., Vidale, P.L., Lüthi, D., Frei, C., Häberli, C., Liniger, M.A., Appenzeller, C, 2004. The role of increasing temperature variability in European summer heatwaves. Nature 427, 332-336.

SIA 2024, 2006. Standard-Nutzungsbedingungen für die Energie- und Gebäudetechnik, SIA, Swiss Association of Engineers and Architects, Zürich.

Taleghani, M., Kleerekoper, L., Tenpierik, M., Van den Dobbelsteen, A., 2014. Outdoor thermal comfort within five different urban forms in the Netherlands. Build. Environ. http://dx.doi.org/10.1016/j.buildenv.2014.03.014.

Tominaga, Y., Mochida, A., Yoshie, R., Kataoka, H., Nozu, T., Yoshikawa, M., Shirasawa, T., 2008. AIJ guidelines for practical applications of CFD to pedestrian wind environment around buildings. J. Wind Eng. Ind. Aerodyn. 96, 1749-1761.

Toparlar, Y., Blocken, B., Vos, P., van Heijst, G.J.F, Janssen, W.D., van Hooff, T., Montazeri, H., Timmermans, H.J.O, 2015. CFD simulation and validation of urban microclimate: A case study for Bergpolder Zuid, Rotterdam. Build. Environ. 83, 79-90.

Watkins, R., Palmer, J., Kolokotroni, M., Littlefair, P., 2002. The London Heat Island - results from summertime monitoring. Build. Serv. Eng. Res. Technol. 23 (2), 97-106.

\section{Figures}




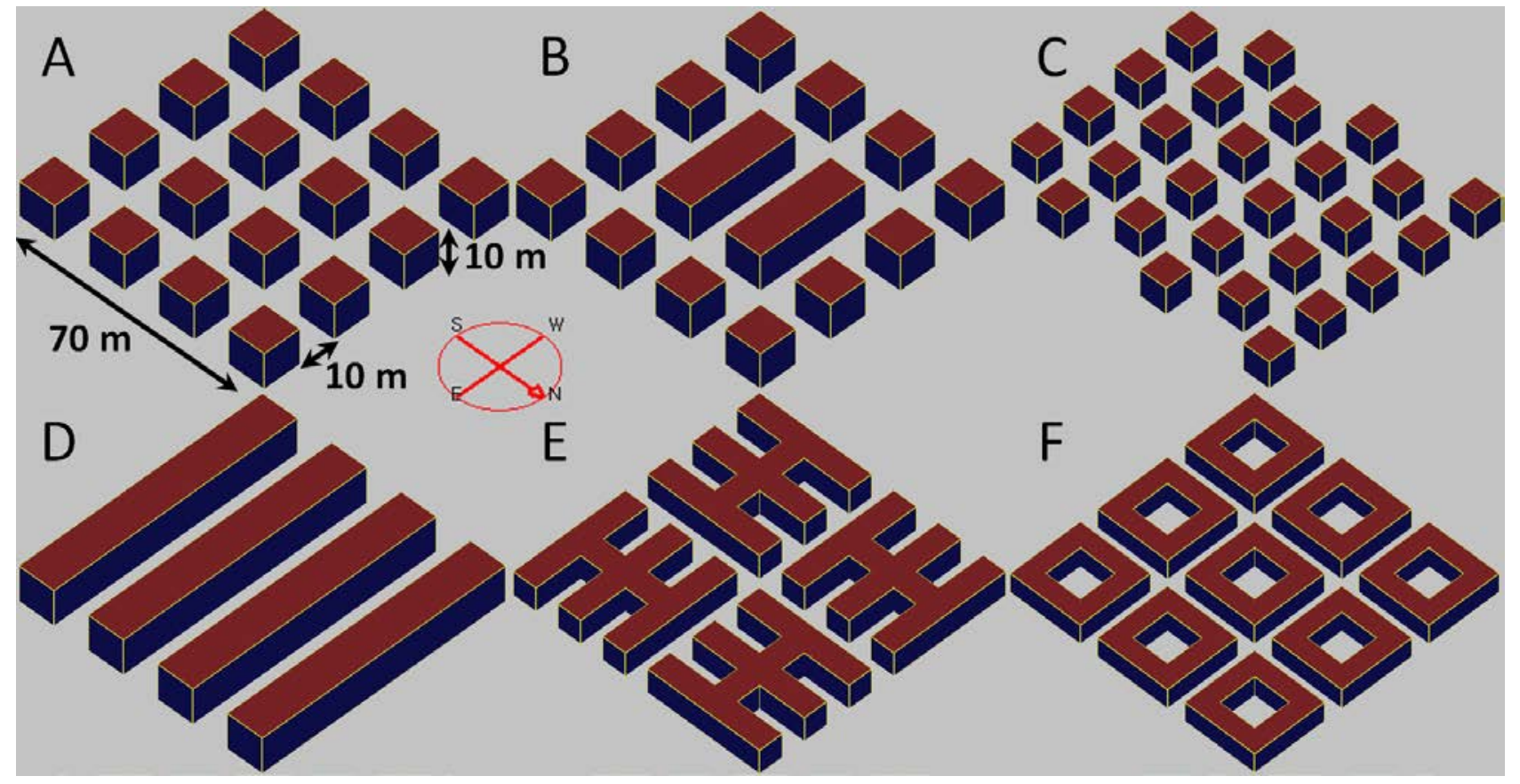

Figure 1: The layout and orientation of the six urban morphologies under investigation.

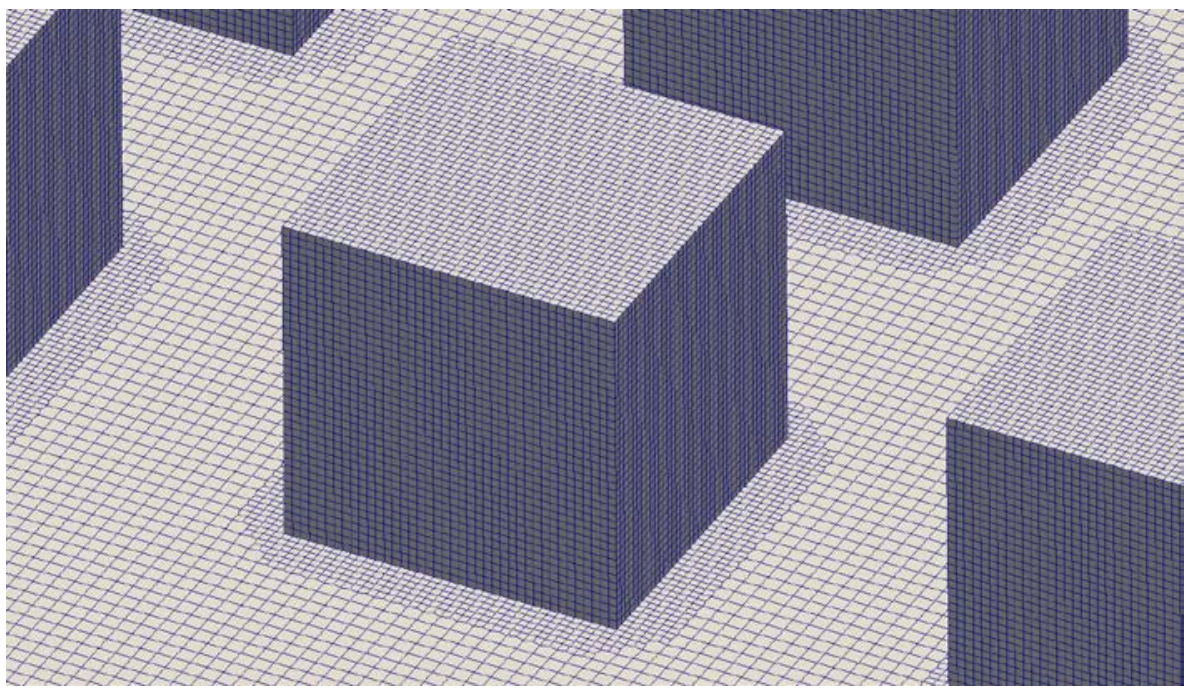

Figure 2: Computational grid around one cubical building.

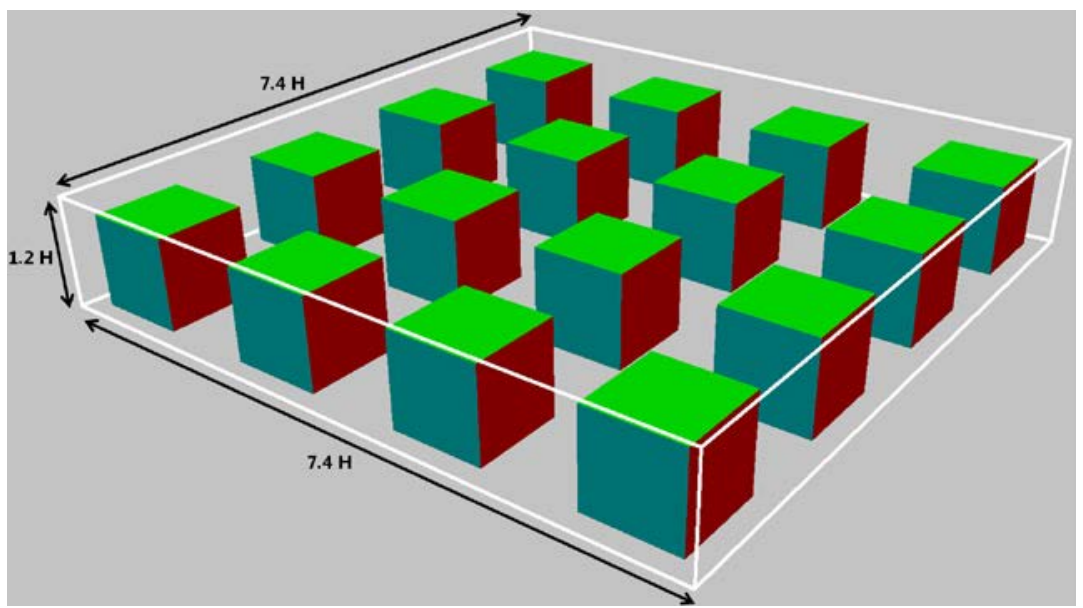

Figure 3: Sketch of the larger control volume around one of the urban morphologies 


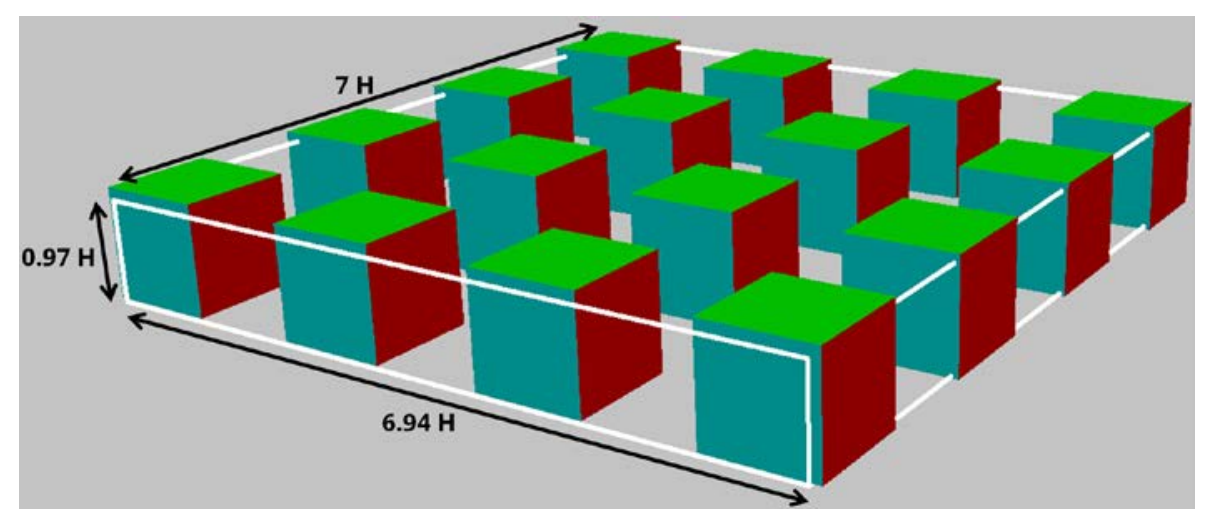

Figure 4: Sketch of the smaller control volume around one of the urban morphologies
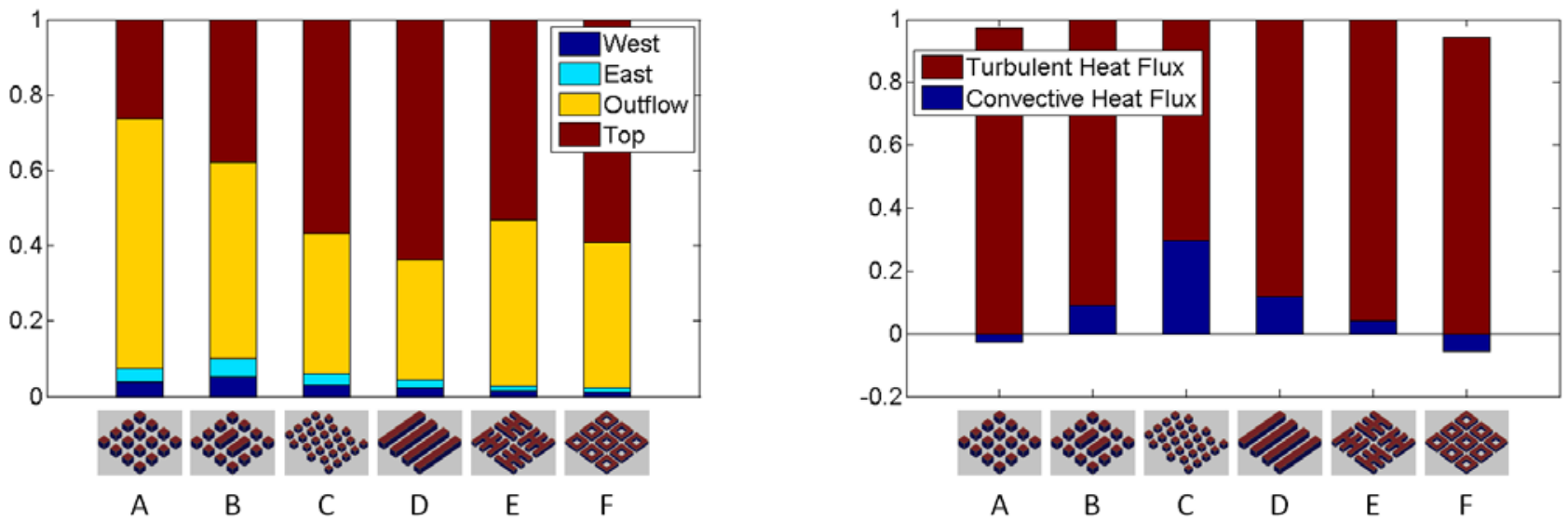

Figure 5: Left: Relative heat fluxes to the environment through the four boundaries for six urban morphologies. The sums of the turbulent and convective heat fluxes from the urban areas to the environment are given. Right: Relative part of the turbulent and convective heat fluxes through the top boundary for six urban morphologies. The values are negative, when the heat fluxes is from the environment to the urban area. Results are for $\mathrm{U}_{10}=5.5 \mathrm{~m} / \mathrm{s}$.
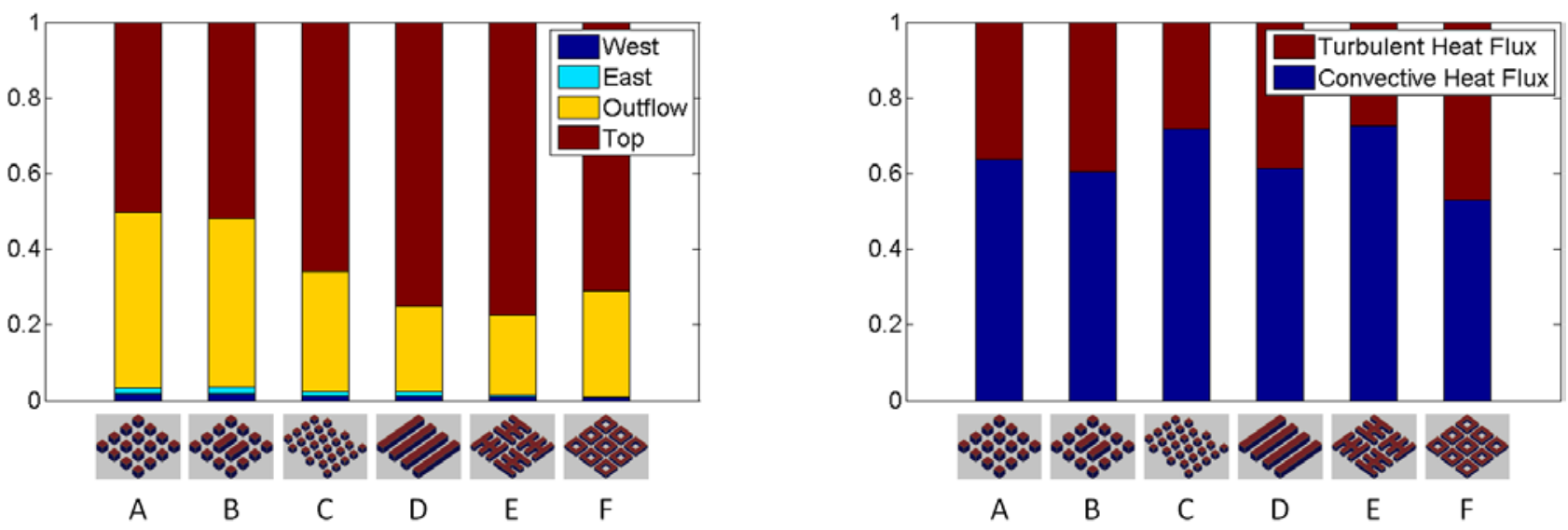

Figure 6: Left: Relative heat fluxes to the environment through the four boundaries for six urban morphologies. The sums of the turbulent and convective heat fluxes from the urban areas to the environment are given. Right: Relative part of the turbulent and convective heat fluxes through the top boundary for six urban morphologies. The values are negative, when the heat fluxes is from the environment to the urban area. Results are for $U_{10}=1 \mathrm{~m} / \mathrm{s}$. 

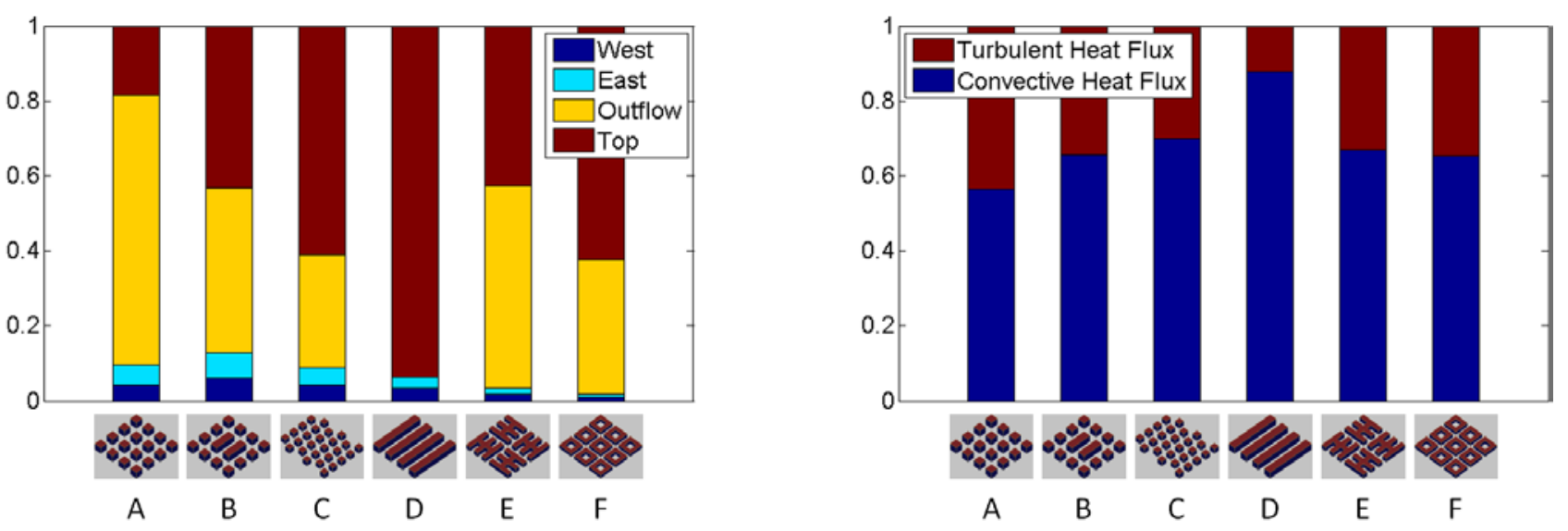

Figure 7: Left: Relative heat fluxes to the environment through the four boundaries for six urban morphologies. The sums of the turbulent and convective heat fluxes from the urban areas to the environment are given. Right: Relative part of the turbulent and convective heat fluxes through the top boundary for six urban morphologies. The values are negative, when the heat fluxes is from the environment to the urban area. Results are for $\mathrm{U}_{10}=5.5 \mathrm{~m} / \mathrm{s}$.

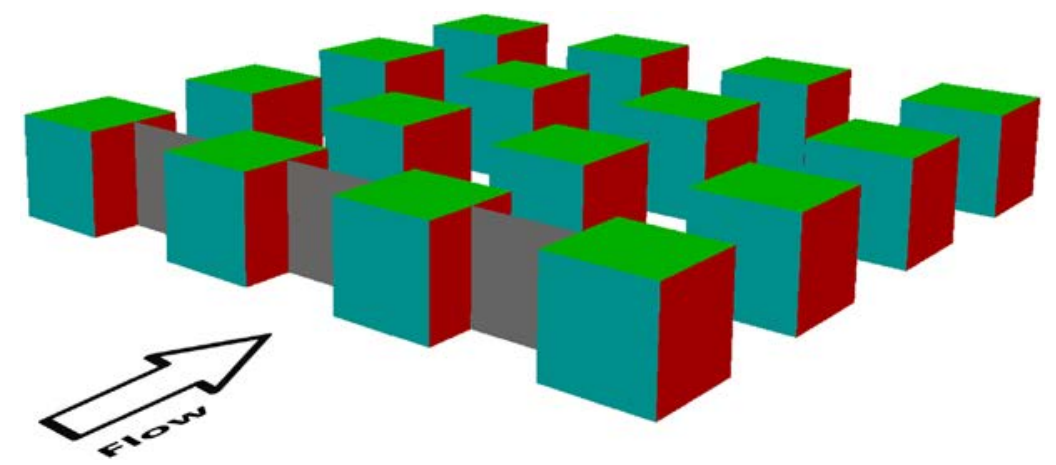

Figure 8: Sketch of a vertical boundary (in grey) for one of the urban morphologies.
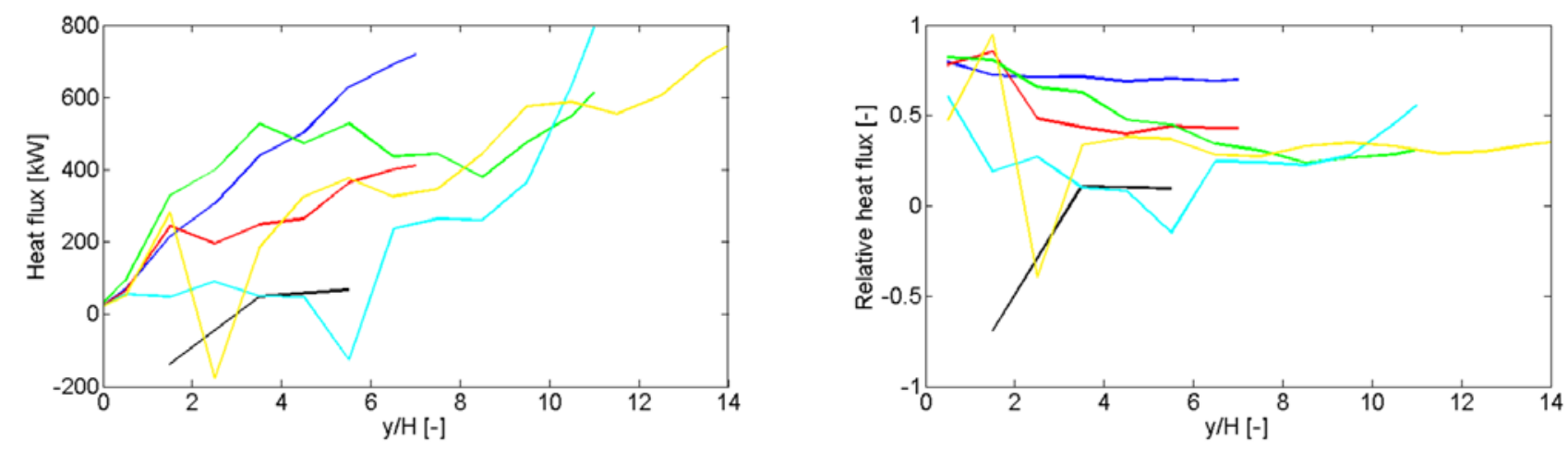

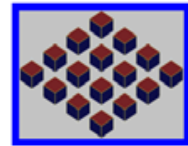

A

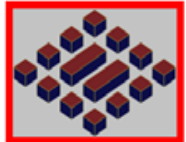

B

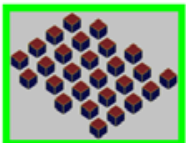

$\mathrm{C}$

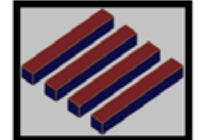

D

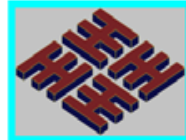

$\mathrm{E}$

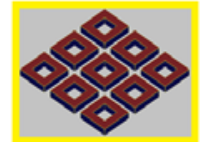

$\mathrm{F}$

Figure 9: Left: Total heat flux through a vertical plane at different downstream positions $(\mathrm{y} / \mathrm{H} ; \mathrm{H}$ : building height) for six urban morphologies. Right: Heat flux through the vertical boundary divided by the numerically integrated upstream wall heat flux at the building facades and ground surface at different downstream positions. Results are for $\mathrm{U}_{10}=5.5 \mathrm{~m} / \mathrm{s}$. 

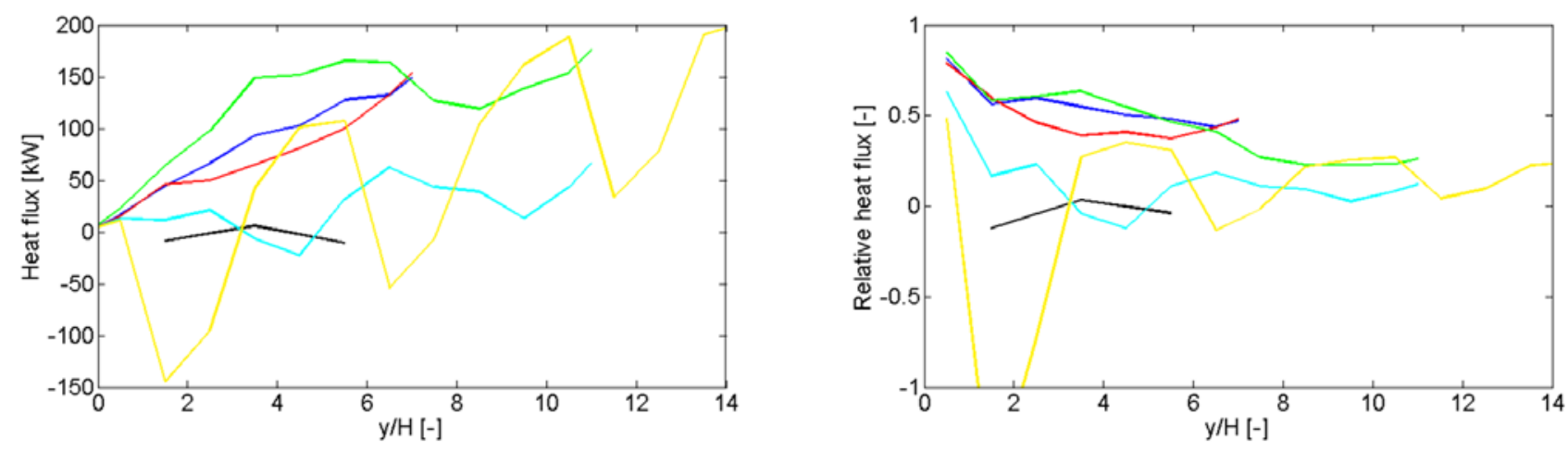

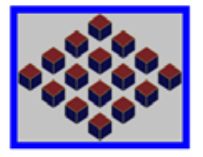

A

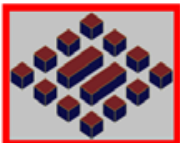

B

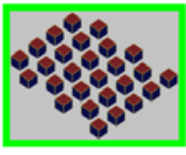

C

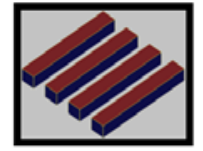

D

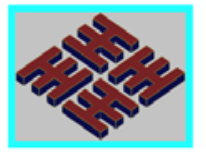

$\mathrm{E}$

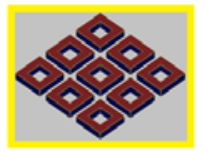

$\mathrm{F}$

Figure 10: Left: Total heat flux through the vertical plane at different downstream positions $(\mathrm{y} / \mathrm{H}$; $\mathrm{H}$ : building height) for six urban morphologies. Right: Heat flux through the vertical boundary divided by the integrated upstream wall heat flux at the building facades and ground surface at different downstream positions. Results are for $U_{10}=1 \mathrm{~m} / \mathrm{s}$.
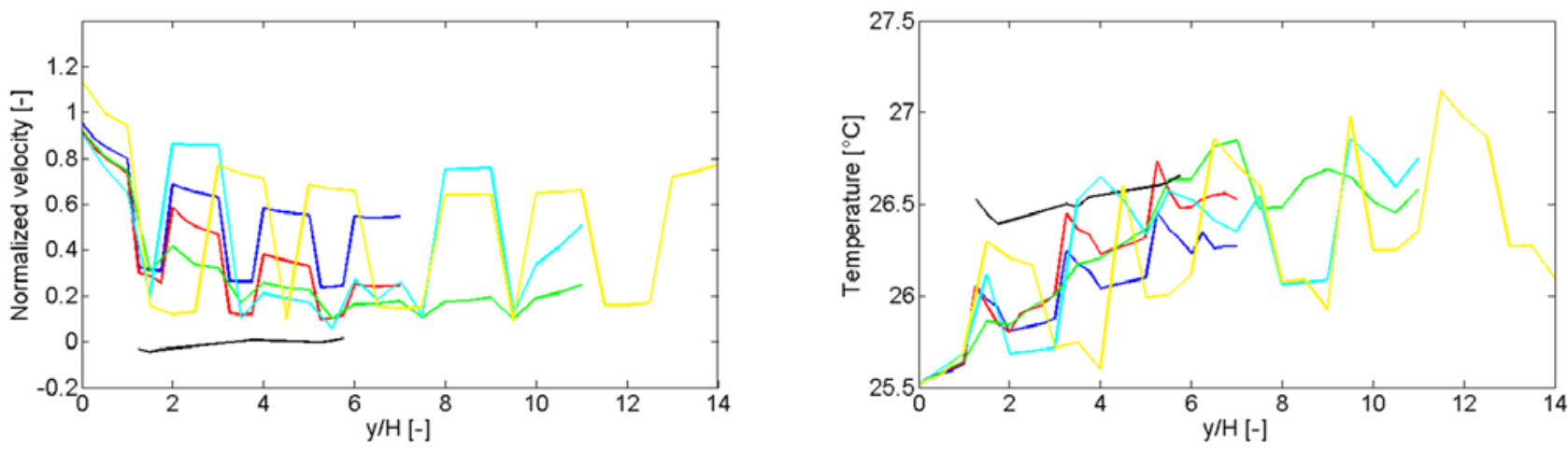

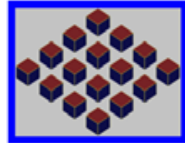

A

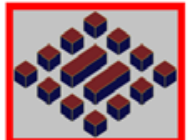

B

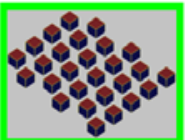

C

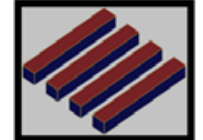

D

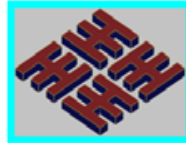

$\mathrm{E}$

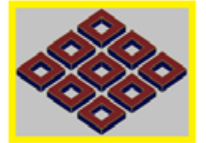

$\mathrm{F}$

Figure 11: Left: Averaged downstream velocities normalized by $U_{10}$ for six urban morphologies on a vertical plane at different downstream positions. Right: Averaged air temperatures for six urban morphologies on a vertical plane at different downstream positions. Results are for $U_{10}=5.5 \mathrm{~m} / \mathrm{s}$. 

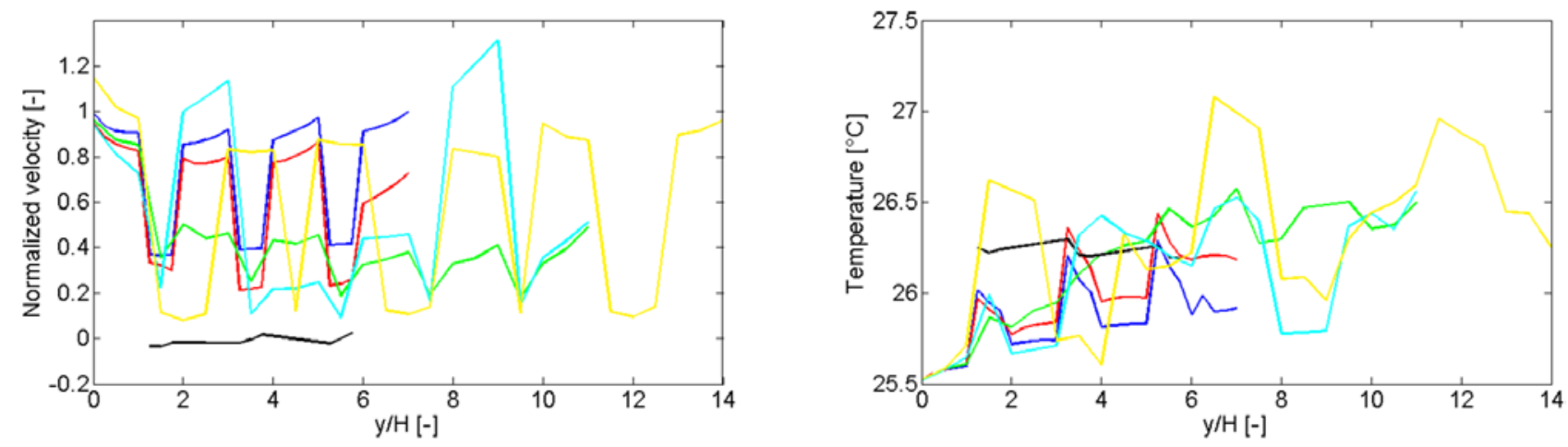

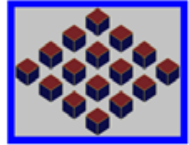

A

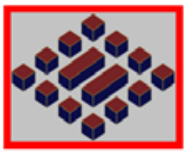

B

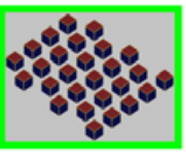

C

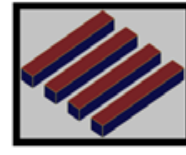

D

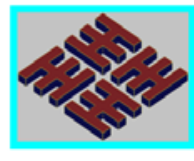

$\mathrm{E}$

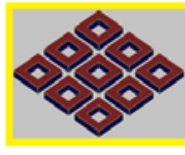

$\mathrm{F}$

Figure 12: Left: Averaged downstream velocities normalized by $\mathrm{U}_{10}$ for six urban morphologies on a vertical plane at different downstream positions. Right: Averaged air temperatures for six urban morphologies on a vertical plane at different downstream positions. Results are for $U_{10}=1 \mathrm{~m} / \mathrm{s}$. 